\title{
Dental procedures in children with severe congenital heart disease: a theoretical analysis of prophylaxis and non-prophylaxis procedures
}

\author{
Z M Al-Karaawi, V S Lucas, M Gelbier, G J Roberts
}

\begin{abstract}
Objective-To estimate the cumulative exposure to bacteraemia from dental procedures currently recommended for antibiotic prophylaxis and compare this with cumulative exposure from dental procedures not recommended for prophylaxis.

Design-Retrospective analysis.

Setting-University and teaching hospital maxillofacial and dental department.

Patients-136 children with severe congenital cardiac disease attending for dental treatment between 1993 and 1998 and for whom full records were available. Each dental procedure was tallied.
\end{abstract}

Main outcome measures-Cumulative exposure per annum to "non-prophylaxis procedures"; cumulative exposure per annum to "prophylaxis procedures".

Results-Cumulative exposure to bacteraemia from prophylaxis procedures was not significantly greater than from non-prophylaxis procedures.

Conclusions-The data raise important questions about the appropriateness of current guidelines for antibiotic prophylaxis of bacterial endocarditis.

(Heart 2001;85:66-68)

Keywords: congenital heart disease; dental treatment; cumulative risk; endocarditis

The reported prevalence of congenital heart disease in western countries is between $4 / 1000$ and $12 / 1000$ live births. ${ }^{1}$ Congenital or acquired abnormalities involving the cardiac endothelium predispose to the risk of bacterial endocarditis. ${ }^{2}$ This may occur following a bacteraemia caused by soft tissue manipulations such as dental treatment or instrumentation of the urinary tract. $^{3}$ The overall reported prevalence of bacterial endocarditis in the general population is between 11 and 50 cases per million annually. ${ }^{4}$ At least $40 \%$ of these cases have no known risk factors. Despite the advent of antibiotics the overall number of cases has not declined. ${ }^{5-7}$

Dental treatment is responsible for only a small proportion of cases of bacterial endocarditis. ${ }^{46-10}$ It is impossible to predict which individuals will develop bacterial endocarditis. ${ }^{112}$ Cumulative exposure to dental bacteraemia from dental filling procedures may be a greater risk than bacteraemia from occasional surgical procedures, such as extractions. ${ }^{10}$ This is of special concern given the relatively high levels of dental disease present in children with heart disease..$^{13}$

There are clear guidelines regarding antibiotic prophylaxis for dental procedures likely to cause bacteraemia. The endocarditis working party of the British Society for Antimicrobial Chemotherapy recommends antibiotic prophylaxis for extractions, scaling, and periodontal surgery. ${ }^{15}$ The American Heart Association $^{12}$ has extended the list of procedures to include placement of dental implants, reimplantation of avulsed teeth, endodontic instrumentation beyond the root apex, and intraligamental injections. There are also various procedures for which antibiotic prophylaxis is not recommended, although recent research shows that they cause significant bacteraemia. These include the use of a matrix band and wedge, and the placement of a rubber dam. ${ }^{16}$ There is also a small background bacteraemia which occurs in approximately $10 \%$ of subjects, ${ }^{16}{ }^{17}$ with Streptococcus sanguis being the most common species isolated. ${ }^{18}$

Our purpose in this study was to estimate the theoretical cumulative exposure to bacteraemia caused by dental procedures. These data were divided into "prophylaxis procedures" and "non-prophylaxis procedures" for statistical comparison.

\section{Methods}

STUDY POPULATION

Ethical approval was obtained from Great Ormond Street Hospital for Children NHS Trust (GOS) and the Eastman Dental Hospital $(\mathrm{EDH})$ research and ethics committee. The children in the study population were receiving all their dental treatment at GOS or $\mathrm{EDH}$ because of the severity of their congenital heart disease.

All the data were taken from the records of children with severe congenital heart disease for the five year period June 1993 to June 1998 at Great Ormond Street Hospital and from January to July 1998 at the Eastman Dental Hospital. From the case records, each dentogingival manipulative procedure was tallied. As some individual patient's records covered less than a year or up to several years, the number of times a dento-gingival manipulative procedure was carried out was standardised on a year to allow comparison between different procedures or groups of procedures. ${ }^{19}$ 
Table 1 UK and US recommendations for antibiotic prophylaxis in cases of congenital heart disease

British Society for Antimicrobial Chemotherapy

American Heart Association ${ }^{12}$

Dental procedures requiring antibiotic prophylaxis

Dental extractions

Periodontal surgery or scaling with or Periodontal procedures including surgery, scaling,

without local anaesthesia

root planing, probing, and recall

Maintenance

Dental implants placement and reimplantation of avulsed teeth

Endodontic (root canal) instrumentation or

surgery only beyond the apex

Subgingival placement of antibiotic fibres or strips

Initial placement of orthodontic bands, but not

brackets

Prophylactic cleaning of teeth or implants where

bleeding is anticipated

Intraligamentary local anaesthetic injections

Dental procedures not requiring antibiotic prophylaxis

Restorative dentistry with or without retraction cord

Local anaesthetic injections

Intracanal endodontic treatment, post-placement

and buildup

Placement of rubber dam

Postoperative suture removal

Placement of removable prosthodontic or

orthodontic appliances

Taking of oral impressions

Shedding of primary teeth

The procedures tallied were then classified as either prophylaxis procedures or nonprophylaxis procedures according to the guidelines of the endocarditis working party of the British Society of Antimicrobial Chemotherapy $(1993)^{15}$ and the American Heart Association (1997). ${ }^{12}$ These are shown in table 1 .

OUTCOME VARIABLES

The main outcome variables derived for this study were: the mean number of dento-gingival manipulative procedures per person per year which were "prophylaxis procedures"; the mean number of dento-gingival manipulative procedures per person per year which were "non-prophylaxis procedures"; and cumulative exposure to bacteraemia for prophylaxis and non-prophylaxis procedures.

The estimate for the cumulative exposure was derived from the equation: intensity $\times$ tally $\times$ prevalence $\times$ duration $=$ cumulative exposure in $\mathrm{cfu} / \mathrm{ml} /$ procedure/year, where
- Intensity is the number of colony forming units (cfu)/ml blood and is derived from several sources. ${ }^{16}{ }^{20-24}$

- Tally is the average number of a given dentogingival manipulative procedure performed annually (these data were derived solely from the present study).

- Prevalence is the number of positive cultures expressed as a proportion; these data were derived from several sources. ${ }^{162-26}$ For purposes of calculation, a percentage prevalence is converted to a proportion, for example: $38 \%=$ 0.38 .

- Duration is the length of bacteraemia, which is 15 minutes. ${ }^{10}$

These data for cumulative exposure were then exported to SPSS for Windows, version 7.0, and the mean and SD for prophylaxis procedures and non-prophylaxis procedures were derived. The cumulative exposure for each procedure was estimated using the above formula. These data (the cumulative exposure) were tested for normality using the ShapiroWilk test. The data were not normally distributed. For this reason the two groups of cumulative exposure-prophylaxis procedures and non-prophylaxis procedures-were compared using the Mann-Whitney U test for independent samples. ${ }^{27}$

\section{Results}

In all, 133 children received treatment at GOS and a further three at EDH, a total of 136 fully documented records. Eighty one children were treated under general anaesthesia, and the remaining 55 were treated using local anaesthesia. There were 79 boys and 57 girls, and the mean (SD) age for the whole group was 10.5 (3.8) years, with a range of $2.3-19$ years. The time over which data were collected for individual patients varied from $0.4-5.8$ years.

AVERAGE NUMBER OF PROCEDURES/YEAR

For each dental procedure the total number of occurrences was divided by the number of years (or part years) to provide an average number/year for each procedure. These were then partitioned into prophylaxis procedures

Table 2 Calculation of the cumulative exposure to odontogenic bacteraemia for prophylaxis and non-prophylaxis procedures

\begin{tabular}{|c|c|c|c|c|c|}
\hline & $\begin{array}{l}\text { Intensity } \\
(c f u / m l)\end{array}$ & $\begin{array}{l}\text { Tally (this } \\
\text { study) (n/year) }\end{array}$ & $\begin{array}{l}\text { Prevalence (from } \\
\text { percentage) }\end{array}$ & $\begin{array}{l}\text { Duration } \\
(\text { min })^{10}\end{array}$ & $\begin{array}{l}\text { Cumulative } \\
\text { exposure }\end{array}$ \\
\hline \multicolumn{6}{|l|}{ Prophylaxis procedures } \\
\hline Scaling & $2.16^{23}$ & 0.13 & $0.4^{23}$ & 15 & 1.685 \\
\hline Single extraction primary tooth & $0.23^{20}$ & 0.04 & $0.43^{20}$ & 15 & 0.059 \\
\hline Single extraction permanent tooth & $1.12^{25}$ & 0.06 & $0.68^{25}$ & 15 & 0.685 \\
\hline Multiple extractions-primary and permanent & $12.77^{20}$ & 0.53 & $0.51^{20}$ & 15 & 51.775 \\
\hline Mucoperiosteal surgery & $63.0^{20}$ & 0.05 & $0.39^{20}$ & 15 & 18.428 \\
\hline \multicolumn{6}{|l|}{ Non-prophylaxis procedures } \\
\hline Dental examination & $0.28^{23}$ & 2.80 & $0.17^{23}$ & 15 & 1.999 \\
\hline Polishing teeth & $5.47^{23}$ & 0.80 & $0.25^{23}$ & 15 & 16.410 \\
\hline Local anaesthetic infiltration & $\star 3.60^{23}$ & 0.57 & $0.16^{23}$ & 15 & 4.925 \\
\hline Rubber dam placement with clamps & $1962^{21}$ & 0.90 & $0.31^{21}$ & 15 & 8210.970 \\
\hline Slow drill & $0.31^{21}$ & 1.78 & $0.12^{21}$ & 15 & 0.993 \\
\hline Fast drill & $1.9^{21}$ & 1.67 & $0.04^{21}$ & 15 & 1.904 \\
\hline Matrix band placement & $4.8^{21}$ & 0.12 & $0.32^{21}$ & 15 & 2.7648 \\
\hline
\end{tabular}

^No data on published studies available. To preserve the mathematical calculation, the pre-procedure or baseline value from a recent unpublished study on children has been substituted.

Prophylaxis procedures $v$ non-prophylaxis procedures: Mann-Whitney $\mathrm{U}$ test, $\mathrm{p}=0.4649$ (NS).

Superscripts are references; cfu, colony forming units. 
and non-prophylaxis procedures (table 2). The US guidelines, ${ }^{12}$ which incorporate the UK guidelines, ${ }^{15}$ were used to partition the data in this way.

\section{CUMULATIVE EXPOSURE}

The theoretical cumulative exposure, expressed as the number of colony forming units $/ \mathrm{ml} \mathrm{blood} / \mathrm{minute}$ in the standardised year, is shown in table 2 . This table combines data from a variety of investigations. The greatest cumulative exposure was from the placement of rubber dam (8849.000). The smallest was from a single primary tooth extraction (0.059). Dental examinations had a cumulative exposure of 1.999 and polishing of teeth with a rubber cup and polishing paste, a cumulative exposure of 16.410 .

\section{Discussion}

The purpose of this study was to estimate the cumulative exposure to odontogenic bacteraemia over a period of a standardised year ${ }^{19}$ in a group of children with severe congenital heart disease. Several dento-gingival manipulative procedures were investigated and divided into two groups following the guidelines of the American Heart Association (1997). ${ }^{12}$ These have been updated more recently than the UK guidelines ${ }^{15}$ which are incorporated within the guidelines from the USA. Of interest was the finding that none of the children in this study received intraligamental analgesic injections. This is reassuring, as the technique is associated with a very high prevalence of bacteraemia. $^{28}$

The two groups compared were procedures that required antibiotic prophylaxis and those that did not. It is clear that the non-prophylaxis procedures present a similar risk of cumulative bacteraemia to the prophylaxis procedures.

A weakness of this study is that these data were derived retrospectively. However, there would be various difficulties in carrying out a prospective study - a very large number of subjects would need to be recruited to obtain sufficient data for statistical analysis, and a large proportion of these children would be dentally fit when examined by their dentist and would not need any active dental treatment. ${ }^{14}$ The results presented here, although retrospective, are from dental treatment completed on a large number of children who are known to be at risk of odontogenic bacteraemia. This has significant clinical implications for the management of children with severe congenital heart disease. These data are applicable to any child with congenital heart disease receiving dental treatment, whether in a hospital dental department, a community dental clinic, specialist practice, or general dental practice. In stating this it is recognised that the rubber dam is not used very often in general dental practice, so its contribution to cumulative exposure may not be as important as the others. Of considerable concern are the high cumulative exposure values obtained from dento-gingival manipulative procedures related to conservative dentistry-procedures not recommended for antibiotic prophylaxis by either UK or US working parties on endocarditis prophylaxis. ${ }^{12} 15$

These data raise questions about the appropriateness of current recommendations for preprocedure antibiotic prophylaxis in children at risk of developing bacterial endocarditis.

1 Hoffman JIE. Incidence of congenital heart disease. I. Postnatal incidence. Pediatr Cardiol 1995;16:103-13.

2 Durack DT, Lukes AS, Bright DK. New criteria for diagnosis of infective endocarditis: utilization of specific echocardiographic findings. Am $\mathcal{F}$ Med 1994;96:200-9.

3 Everett ED, Hirschmann JV. Transient bacteraemia and Everett ED, Hirschmann JV. Transient bacteraemia and
endocarditis prophylaxis. A review. Medicine 1977;56:6177 .

4 van der Meer JTM, Thompson J, Michel MF, et al. Epidemiology of bacterial endocarditis in the Netherlands. I. Patient characteristics. Arch Intern Med 1992;152:1863-8.

5 Oakley C, Somerville W. Prevention of infective endocarditis. Br Heart $\mathcal{F}$ 1981;45:233-5.

6 Bayliss R, Clarke C, Oakley C, et al. The teeth and infective endocarditis. Br Heart f 1983;50:506-12.

7 Kaye, D. Prophylaxis for infective endocarditis: an update. Ann Intern Med 1999;104:419-23.

Pogrel MA, Welsby PA. The dentist and prevention of infective endocarditis. Br Dent F 1975;139:12-16.

9 Cawson RA. Infective endocarditis as a complication of dental treatment. Br Dent f 1981;151:409-14.

10 Guntheroth WG. How important are dental procedures as a cause of infective endocarditis? Am f Cardiol 1984;54:797801 .

11 Harvey WP, Capone MA. Bacterial endocarditis related to cleaning and filling of teeth. Am f Cardiol 1961;7:793-8.

12 Dajani AS, Taubert KA, Wilson W, et al. Prevention of bacerial endocarditis. Recommendations by The American Heart Association. fAMA 1997;277:1794-801.

13 Pollard MA, Curzon MEJ. Dental health and salivary streptococcus mutans levels in a group of children with heart defects. Int $\mathcal{F}$ Paediatr Dent 1992;2:81-5.

4 Franco E, Saunders C, Roberts GJ, et al. Dental disease, caries related microflora and salivary IgA of children with severe congenital cardiac disease. Pediatr Dent 1996;18: 228-35

15 Endocarditis Working Party of the British Society for Antimicrobial Chemotherapy. Recommendations for endocarditis prophylaxis. F Antimicrob Chemother 1993;31:437-8.

16 Roberts GJ, Holzel H, Sury M, et al. Dental bacteraemia in children. Pediatr Cardiol 1997;18:24-7.

17 Farrington $\mathrm{FH}$. The incidence of transient bacteremia following pulpotomies on primary teeth. $\mathcal{F}$ Dent Child 1973; May-June:175-84

18 Shanson DC. Septicaemia and endocarditis. Clinical and microbiological aspects. Oxford: Oxford University Press, 1989

19 Hennekens $\mathrm{CH}$, Buring SL. Epidemiology in medicine. Boston: Little Brown, 1987:55.

20 Roberts GJ, Watts R, Longhurst P, et al. Bacteraemia of dental origin and antimicrobial sensitivity following oral surgical procedures in children. Pediatr Dent 1998;20:2836.

21 Roberts GJ, Gardner P, Longhurst P, et al. Intensity of bacteraemia associated with conservative dental procedures in children. Br Dent F 2000;188:95-8.

22 Roberts GJ, Radford P, Holt R. Prophylaxis of dental bacteraemia with oral amoxycillin in children. $\mathrm{Br}$ Dent $\mathcal{F}$ 1987;162:179-82.

3 Roberts GJ. Odontogenic bacteraemia in children. London: University of London, 1997. [Thesis.]

24 Lytra V. Lysis filtration for the detection of bacteraemia in children. London: University of London, 1998. [MSc dissertation.]

25 Heimdahl A, Hall G, Hedberg $M$, et al. Detection and quantification by lysis filtration of bacteraemia after different oral surgical procedures. F Clin Microbiol. 1990;28: 2205-9.

26 van der Meer JTM. Endocarditis prophylaxis: fact or fiction? 1 st ed. The Hague: CIP-Gegevens Koninklijke Bibliotheek, 1992:1-111

27 Altman DG. Practical statistics for medical research. London: Chapman and Hall, 1991.

28 Roberts GJ, Simmons NB, Longhurst PB, et al. Bacteraemia following local anaesthetic injections in children. Br Dent $\mathcal{F}$ 1998;185:295-8. 